\title{
Plasma concentrations of L-dopa and 3-methoxydopa and improvement in clinical ratings and motor performance in patients with Parkinsonism treated with L-dopa alone or in combination with amantadine
}

\author{
J. B. PILling, ${ }^{1}$ JANET BAKER, L. L. IVERSEN, \\ S. D. IVERSEN, AND T. ROBBINS
}

\begin{abstract}
From the Department of Neurological Surgery and Neurology, Addenbrookes Hospital, the MRC Neurochemical Pharmacology Unit, Department of Pharmacology, and the Department of Experimental Psychology, University of Cambridge, Cambridge
\end{abstract}

SYNOPSIS Six patients with idiopathic Parkinsonism were treated with a combination of amantadine and L-dopa and after 12 to 24 weeks amantadine was replaced by placebo for a six week period in a double-blind trial. Although there was a tendency for clinical disability ratings and scores on objective ratings of motor skills to deteriorate initially after amantadine removal, there was no significant deterioration in clinical improvement or motor performance during the period of amantadine withdrawal. Amantadine withdrawal also failed to cause any significant change in plasma concentrations of L-dopa or its metabolite 3-methoxy-dopa in these patients. In a group of 27 patients seen regularly as outpatients measurements of plasma L-dopa failed to correlate significantly with either oral dose or with clinical improvement scores. The plasma concentration of 3-methoxy-dopa, however, was on average 2.8 times higher than that of L-dopa, and there was a significant correlation between plasma levels of this metabolite and clinical improvement. It is suggested that 3-methoxy-dopa may contribute significantly to the therapeutic actions of L-dopa in Parkinsonism.

Amantadine and L-dopa are in widespread use, either singly or in combination, in the treatment of patients with Parkinsonism. The combination of amantadine and L-dopa has been claimed to be more effective than L-dopa alone, although not all trials have confirmed this synergism (for review see Parkes et al., 1973). Amantadine has also been shown to decrease the daily L-dopa therapeutic dosage requirements and it has been suggested that amantadine may decrease the extracerebral metabolism of L-dopa, thus rendering more drug available to the central nervous system (Peaston et al., 1973). In the present study we present clinical and biochemical findings in a group of patients treated with the combination

\footnotetext{
1 Present address: Department of Neurology, St. Bartholomew's Hospital, London E.C.1. (Accepted 16 August 1974.)
}

of L-dopa and amantadine, or with L-dopa alone which do not appear to support the latter conclusions. In addition, we report that only a poor correlation exists between plasma concentrations of L-dopa and clinical improvement in patients with Parkinsonism, although there is a significant correlation with the plasma concentration of the metabolite 3-methoxy-dopa.

\section{METHODS}

ISOLATION AND ESTIMATION OF L-DOPA AND 3METHOXYDOPA IN PLASMA SAMPLES Plasma samples were stored at $-20^{\circ} \mathrm{C}$ for up to two weeks before isolation of the amino acids and fluorimetric assay; preliminary experiments showed that both compounds were stable under these storage conditions. Plasma samples $(4 \mathrm{ml})$ were deproteinized by addition of $4 \mathrm{ml}$ ice-cold $0.4 \mathrm{~N}$ perchloric acid, and stand- 
ing for at least 15 minutes at ice temperature. The samples were centrifuged and the supernatant fluid adjusted to $\mathrm{pH} 2.0$ by addition of potassium hydroxide. The supernatants were then passed through columns $(2.5 \mathrm{~cm} \times 0.6 \mathrm{~cm}$ diameter $)$ of the ion exchange resin Amberlite CG-120-Type II- $\mathrm{H}^{+}$form. The resin was washed with $10 \mathrm{ml}$ distilled water, and both amino acids eluted in $10 \mathrm{ml}$ of a $0.1 \mathrm{M}$ sodium phosphate buffer pH 6.5. In experiments in which known amounts of L-dopa or 3-methoxydopa were added to plasma samples the average recovery of L-dopa was found to be $90 \pm 2 \%$ and of 3-methoxydopa $73 \pm 3 \%($ mean $\pm \operatorname{SE~} n=12)$. All values were corrected for these recoveries.

L-dopa was assayed in $1 \mathrm{ml}$ samples of the eluate by addition of $0.05 \mathrm{ml} 0.25 \%(\mathrm{w} / \mathrm{v})$ potassium ferricyanide, and after three minutes addition of $1.5 \mathrm{ml}$ of alkaline ascorbic acid ( $9 \mathrm{vol} 5 \mathrm{~N}$ sodium hydroxide: 1 vol $2 \%$ ascorbic acid). After mixing and standing at room temperature for $\mathbf{3 0}$ minutes samples were read in a spectrofluorimeter with excitation wavelength = $370 \mathrm{~nm}$ and recording $=520 \mathrm{~nm}$. Blank samples of eluate were treated in the same way except that sodium hydroxide was added three minutes before the addition of the ascorbic acid; 'faded' blanks of this type gave readings not significantly different from those of reagent blanks, in which $1 \mathrm{ml}$ of phosphate buffer was used in place of an eluate sample. The sensitivity of this assay-that is, the amount of amino acid needed to give readings twice as great as those of blank samples-was $16 \mathrm{ng} \mathrm{L}$-dopa. Concentrations in plasma down to $0.05 \mu \mathrm{g} / \mathrm{ml}$ could be accurately measured.

3-Methoxydopa was assayed in parallel $1 \mathrm{ml}$ aliquots of the eluates by a method similar to that described for homovanillic acid by Andén et al. (1963), for 3-methoxydopamine by Guldberg et al. (1971) and for 3-methoxydopa by Fahn et al. (1972). To a $1 \mathrm{ml}$ sample eluate, $1 \mathrm{ml}$ of concentrated $(33 \%)$ ammonia containing $20 \mu \mathrm{g}$ potassium ferricyanide/ $\mathrm{ml}$; two minutes later $0.1 \mathrm{ml}$ of cysteine solution $(1 \mathrm{mg} / \mathrm{ml})$ was added. After five minutes the samples were read in a spectrofluorimeter at excitation wavelength $=315 \mathrm{~nm}$ and recording $=430 \mathrm{~nm}$. The sensitivity of this assay was $20 \mathrm{ng}$ 3-methoxydopa, and concentrations down to $0.10 \mu \mathrm{g} / \mathrm{ml}$ in plasma could be measured. The presence of L-dopa did not interfere with this assay procedure, nor did the presence of 3-methoxydopa interfere with the fluorimetric assay of $\mathrm{L}$-dopa.

CLINICAL ASSESSMENTS In a group of 27 patients seen regularly as outpatients an assessment of disability was made on the basis of clinicians' notes of the interview; this gave a five point disability rating as follows: $0=$ normal activities; $1=$ slight dis- ability, but still working in full time employment or housework; 2 =moderate disability-not in full time employment or needs aid in housework; $3=$ fairly severe disability - some help needed in feeding and dressing; $4=$ severe disability-chair-bound and considerable help needed in feeding and dressing.

In a smaller group of six patients with idiopathic Parkinsonism taking part in a special study of the use of the drug combination L-dopa + amantadine, the patients were seen at frequent intervals and assessed by more detailed questionnaire and physical examination. An overall disability rating on a scale of 0-32 maximum was determined by scoring $0-8$ on the following parameters: tremor, rigidity $(0-2$ in each limb), gait, and 0-4 on finger dexterity and facial expression modified from Dallos et al. (1970). All assessments were made by a single observer (J.B.P.). A rating of 0-63 maximum for 'activities of daily life' was also determined by scoring the following: movement in bed, movement out of bed, washing, eating, dressing, and communication in a proforma modified from that described by GodwinAusten et al. (1969). These patients were assessed at intervals of two weeks for periods of up to 44 weeks; they were all treated initially with the combination L-dopa + amantadine, and placebo tablets were substituted for amantadine for a six week period after stabilization on the drug combination (12-24 weeks after commencing the study). The substitution of placebo was carried out in a double-blind manner, drug allocation being made by the pharmacist.

FORMAL ASSESSMENT OF MOTOR SKILLS The patient sat facing a horizontal testing board with circular metal discs mounted on its long axis. He was instructed either to hold a stylus in the preferred hand or a pair of styli, depending on the test, and to touch the targets in specified sequences. A set of tasks of increasing difficulty was presented. Before each of the tasks clear instructions and a demonstration were given, the patient being allowed to practise briefly before the actual test trials were run. On each test he was asked to make as many of the specified movements as possible during a 10 second interval. The importance of accuracy rather than speed was emphasized. Touching a stylus to a disc completed an electrical circuit and permitted automatic recording of successful movements. On each test two trials were given and at least 30 seconds elapsed both between trials and between tests. Nine tests were used:

1. Gross tapping Alternate tapping between two vertical plates raised $8 \mathrm{~cm}$ above the surface of the board.

2. Continuous tapping Continuous tapping of a centrally placed disc $(5.5 \mathrm{~cm})$. 
3. Alternate tapping (i) Tapping between two large $(5.5 \mathrm{~cm})$ discs placed $50 \mathrm{~cm}$ apart on the board. (ii) Similar tapping between two small $(3.5 \mathrm{~cm})$ discs $50 \mathrm{~cm}$ apart. (iii) Repeated with the large discs $25 \mathrm{~cm}$ apart. (iv) Repeated with the small discs $25 \mathrm{~cm}$ apart.

For the remaining tests four large $(5.5 \mathrm{~cm})$ discs were arranged on the board as follows:

$$
125 \mathrm{~cm}^{2} 25 \mathrm{~cm}^{3} 25 \mathrm{~cm}^{4}
$$

4. Bimanual parallel A second stylus was provided and the patient asked to tap with both hands between pairs of discs $25 \mathrm{~cm}$ apart, placed to the left and right side of the board - that is, to alternate simultaneously between 1 and 2 with one hand and between 3 and 4 with the other. Starting positions were 1 and 3.

5. Converge/diverge The discs remained in the same positions and the patient was asked to use both hands and to tap simultaneously between 2 and 1 and 3 and 4 , starting at positions 2 and 3 .

6. Patterned tapping The preferred hand only was used and the patient asked to tap between 1 and 3 until a verbal signal was given (after five seconds), whereupon he was required to change as quickly as possible to tapping between 2 and 4 . The trial then continued until 10 seconds had elapsed.

The patients were tested on this battery of tests on each hospital visit immediately after the clinical assessment had been made. Testing continued when the L-dopa dose had reached its clinical maximum and during the double blind experiment with amantadine withdrawal.

STATISTICAL ANALYSIS Values for dosage of L-dopa (in $\mathrm{mg} / \mathrm{kg}$ ), in absolute dose per day, size of last dose, and time interval from last dose to time of blood sampling, and plasma concentrations of L-dopa and 3-methoxydopa, together with clinical rating scores were assembled in a table and a FORTRAN programme written to calculate the matrix of partial correlation coefficients, using the method of Draper and Smith (1966). These coefficients were tested for significance by reference to a table of the distribution of $r$ (Dixon and Massey, 1969, Table 30). The Kendall rank correlation coefficient (Conover, 1971) was used for analysis of the relationships between these variables and the ordinal data of the disability rating scales. A FORTRAN programme was written to compute and test the significance of the relationships between the disability scale and each of the other variables, including also the number of days since starting L-dopa therapy.

\section{RESULTS}

COMBINATION OF L-DOPA AND AMANTADINE Five of the six patients examined showed a marked improvement in clinical state during treatment with the drug combination, this improvement was seen by a significant reduction in both the 'disability' and 'activities of daily life' ratings, which tended to continue for the entire period of the trial-up to 40 weeks after commencing treatment (see for example, Fig. 1). The dose of L-dopa was stabilized after eight to 12 weeks and

\section{TABLE 1}

CLINICAL RATING AND PLASMA L-DOPA AND 3-METHOXYDOPA CONCENTRATION IN PATIENTS TREATED WITH L-DOPA OR COMBINATION OF L-DOPA AND AMANTADINE

\begin{tabular}{llccc}
\hline & \multicolumn{2}{c}{ Rating } & $\begin{array}{c}\text { L-dopa } \\
(\mu \mathrm{g} / \mathrm{ml})\end{array}$ & $\begin{array}{c}3-\text { methoxy- } \\
\text { dopa } \\
(\mu \mathrm{g} / \mathrm{ml})\end{array}$ \\
\cline { 2 - 5 } & Disability & $\begin{array}{c}\text { Daily } \\
\text { activities }\end{array}$ & & - \\
\hline $\begin{array}{c}\text { Pre-therapy } \\
\text { values }\end{array}$ & $13.0 \pm 1.93$ & $27.3 \pm 1.68$ & - & \\
$\begin{array}{c}\text { After stabilizing } \\
\text { treatment } \\
\text { with L-dopa } \\
+ \text { amantadine }\end{array}$ & $3.9 \pm 0.08$ & $10.7 \pm 2.04$ & $0.57 \pm 0.131$ & $1.38 \pm 0.350$ \\
$\begin{array}{c}\text { During six week } \\
\text { period of } \\
\text { amantadine } \\
\text { removal }\end{array}$ & $5.7 \pm 1.45$ & $8.8 \pm 2.42$ & $0.71 \pm 0.280$ & $1.46 \pm 0.542$ \\
\hline
\end{tabular}

All values are means \pm SEM for six patients, each value is the average for a six week period (three measurements) before commencing any drug therapy after stabilization on L-dopa + amantadine (12-24 weeks after commencement) and during a six week period in which placebo tablets were substituted for amantadine in a double blind manner. Disability and daily activity ratings are explained in detail in text in the Methods section; improvement in each case is shown by a decreased rating when compared with pre-therapy values. None of the values measured during the period in which amantadine was removed were significantly different from those obtained with the combination of drugs.

was between 1.5 and $3.0 \mathrm{~g}$ per day. The maximum dose of L-dopa was limited by the appearance of involuntary movements in two subjects, gastrointestinal upset in two subjects, and good therapeutic response in two. The dose of amantadine was constant at $300 \mathrm{mg}$ per day. During the period of placebo substitution for amantadine, keeping the dose of L-dopa constant, there was a tendency for the clinical disability rating to deteriorate at least initially but this finding was not statistically significant, nor were there any 


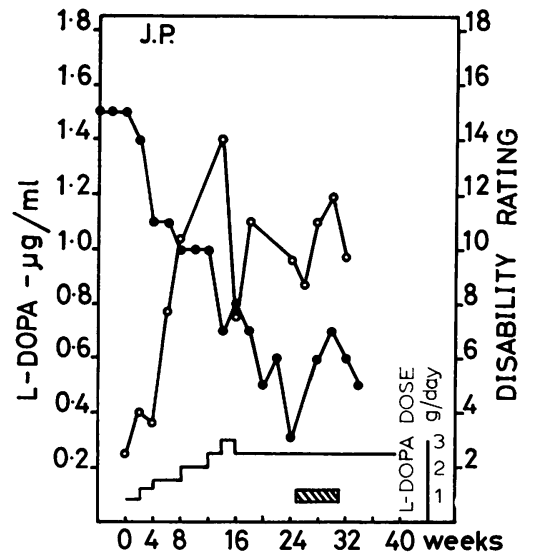

FIG. 1 Plasma L-dopa concentration $(\bigcirc)$, disability rating score (O), and oral dose of $L$-dopa in one patient during a 33 week period after onset of treatment with L-dopa and amantadine (300 mg per day). Amantadine replaced by placebo for a six week period from week 24 .

notable changes in the 'activities of daily life' ratings (Table 1). During this period there were also no significant changes in plasma concentrations of L-dopa or of 3-methoxydopa (Table 1, Fig. 1). The concentrations of $L$-dopa and 3methoxydopa in plasma were determined one to four hours after the last dose of L-dopa, at 14 day intervals during the period of the study. Plasma concentrations of L-dopa varied considerably between patients and in samples taken

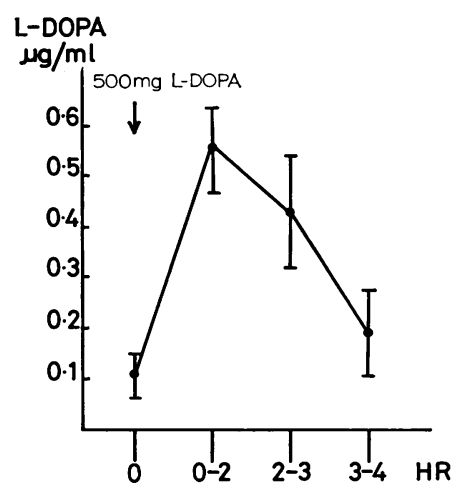

FIG. 2 Plasma concentrations of L-dopa in serial samples of blood taken after an oral dose of $500 \mathrm{mg}$ L-dopa. Mean values \pm SEM for four patients. at different times from the same patient, although an approximately constant level was reached in most patients soon after the dose of L-dopa was stabilized (Fig. 1). This concentration ranged however, from values of $1 \mu \mathrm{g} / \mathrm{ml}$ or more (as in Fig. 1) to values as low as $0.2-0.3 \mu \mathrm{g} / \mathrm{ml}$ in other patients. There was little or no obvious correlation between clinical improvement and plasma concentration of L-dopa, the one patient who failed to respond to drug treatment had plasma concentrations of amino acid in the normal range.

PLASMA CONCENTRATIONS OF L-DOPA AND 3METHOXYDOPA IN OUTPATIENT GROUP There was again a wide variation in plasma concentrations of L-dopa and its metabolite 3-methoxydopa between patients, and between samples from the same patient taken at different times. Part of this variation stems from the difficulty of obtaining plasma samples at a fixed time interval

\section{TABLE 2}

MULTIPLE CORRELATION COEFFICIENTS FOR CLINICAL RATINGS AND BIOCHEMICAL RESULTS OF PATIENTS ON L-DOPA THERAPY

\begin{tabular}{lccc}
\hline Parameter & \multicolumn{3}{c}{ Correlation coefficient with } \\
\cline { 2 - 4 } & $\begin{array}{c}\text { Clinical } \\
\text { rating }\end{array}$ & $\begin{array}{c}\text { Plasma } \\
\text { L-dopa }\end{array}$ & $\begin{array}{c}\text { Plasma } \\
\text { methoxydopa }\end{array}$ \\
\hline L-dopa dose (mg/kg) & - & 0.100 & 0.113 \\
L-dopa daily dose (g) & - & 0.107 & 0.140 \\
L-dopa last dose (mg) & $-0.267^{*}$ & 0.039 & 0.007 \\
Time after last dose & 0.066 & $0.269 \dagger$ & 0.154 \\
Plasma L-dopa & 0.014 & - & $0.669 \ddagger$ \\
Plasma methoxydopa & $-0.325^{*}$ & $0.669 \ddagger$ & - \\
Time after start of therapy & $-0.210 \dagger$ & - & -
\end{tabular}

Correlation coefficients were computed as described in text, using the values obtained from all patients involved in the study.

$* \mathbf{P}<0.05$. $\quad+\mathrm{P}<0.01$. $\quad \mathrm{P}<0.001$.

after the last dose of L-dopa in an outpatient population. In a small number of hospitalized patients serial blood samples were obtained after a single oral dose of $500 \mathrm{mg} \mathrm{L}$-dopa, and the results from these showed that plasma concentrations of L-dopa reach a maximum within two hours after a dose of the drug and decline in the following two hours (Fig. 2). In the samples from the small number of patients studied in the drug combination experiment, average values of 


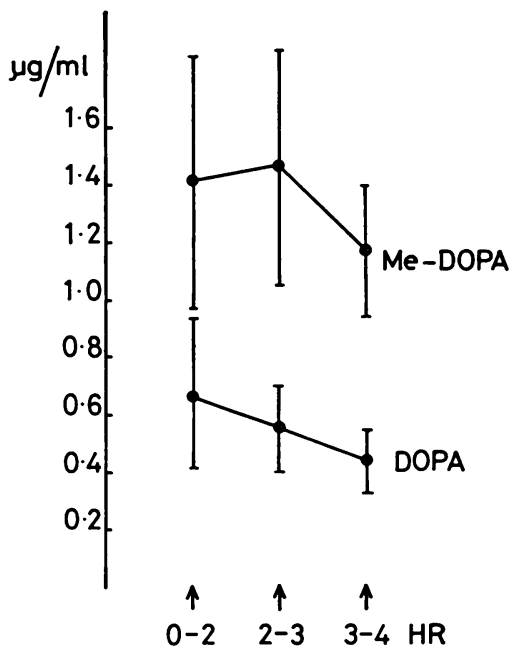

FIG. 3 Mean values for plasma L-dopa and 3methoxydopa at various times after last dose for six patients assessed at regular intervals during treatment with 1.5-3.5 g L-dopa per day. Values were collected at various times after last dose during the course of the trial, and are not serial samples as in Fig. 2; means \pm $S E$ for six to 18 values.

the data acquired during the trial showed a similar decrease in L-dopa concentrations with time after last dose (Fig. 3), although plasma concentrations of 3-methoxydopa did not seem to fluctuate as markedly with time interval after last dose (Fig. 3).

Plasma concentrations of 3-methoxydopa were consistently higher than those of L-dopa. In 27 patients in which the plasma concentrations of the two metabolites were estimated two to three hours after the last dose of L-dopa the concentration of 3-methoxydopa was greater than that of L-dopa in every case, the mean ratio 3-methoxydopa/dopa in these 27 patients being $2.84 \pm 1.59$ (SD). Absolute values for 3-methoxydopa ranged from 0.4-4.0 $\mathrm{ml}$ (Table 2).

Statistical analysis of these results showed that there was a highly significant correlation of plasma L-dopa and methoxydopa concentrations with one another (Table 2). Neither concentration, however, correlated significantly with the dosage of L-dopa used. There was a significant correlation between plasma L-dopa concentration and time interval between administration of last dose and blood sampling. Clinical rating

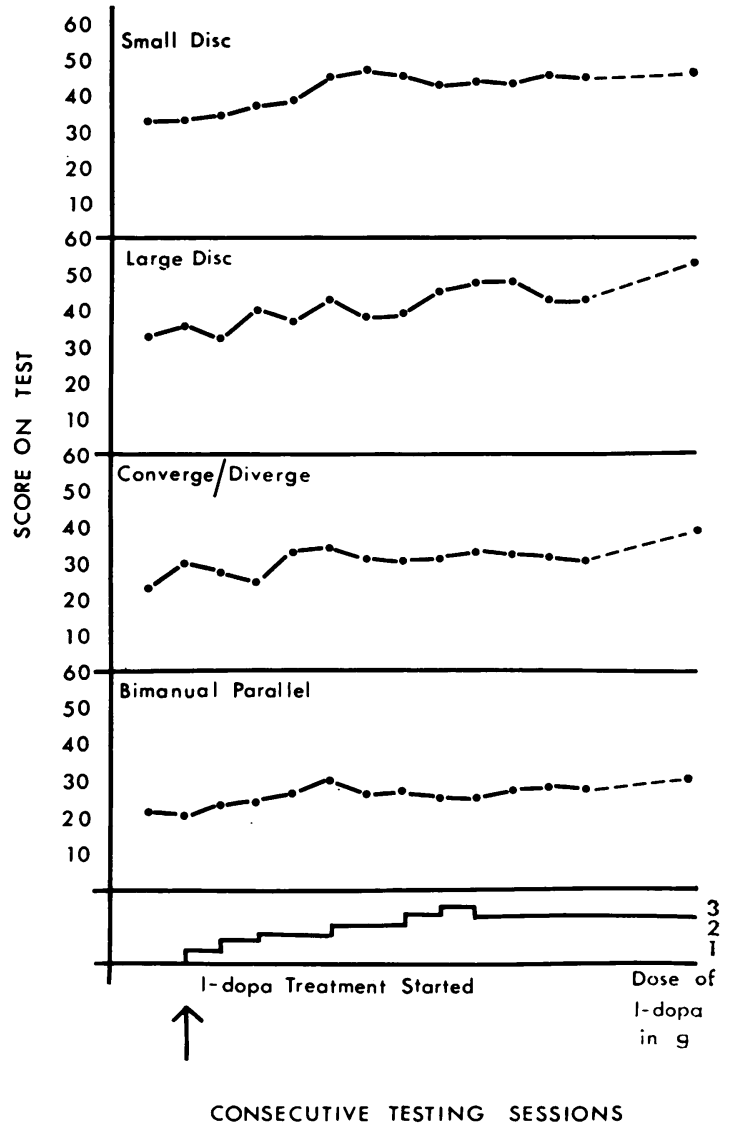

FIG. 4 Gradual improvement of a patient (J.P., $c f$ Fig. 1) in motor performance during treatment.

scores correlated significantly with time after start of therapy, and surprisingly with plasma methoxydopa but not with plasma L-dopa values (Table 2).

MOTOR PERFORMANCE WITH COMBINATION OF L-DOPA AND AMANTADINE Five of the six patients studied showed a steady improvement on the various motor tests during the weeks that the combination treatment was given and the L-dopa dose increased. The performance in one patient on four of the tasks (J.P. for whom the plasma L-dopa/disability rating correlation is illustrated in Fig. 1), is presented to illustrate the gradual improvement in formal motor acts (Fig. 4). 
DOUBLE-BLIND AMANTADINE WITHDRAWAL During amantadine withdrawal deterioration in performance was initially noted in some patients but this recovered during the weeks of the trial. When the full set of test results over the six sessions was subjected to a split plot analysis of variance, amantadine withdrawal was shown not to have a significantly detrimental effect when compared with placebo control treatment on the performance level on the formal motor tests $(\mathrm{F}<1.00 \mathrm{NS})$.

\section{DISCUSSION}

The present results do not support previous conclusions that the combination of L-dopa and amantadine is more effective than L-dopa alone in the treatment of patients with Parkinson's disease. We also failed to find any significant alterations in plasma concentrations of L-dopa or its metabolite 3-methoxydopa in patients treated with L-dopa alone or in combination with amantadine. It is possible that our sample of patients was not sufficiently large, however, to be truly representative, since there was some tendency for clinical disability rating scores to deteriorate during a period of amantadine removal in patients treated with the drug combination.

In a larger group of patients with Parkinsonism treated with L-dopa we were unable to detect significant correlations between plasma concentrations of L-dopa and clinical improvement. Plasma concentrations of 3-methoxydopa, however, were high relative to those of L-dopa in all patients, and there was a significant correlation between these values and clinical improvement. 3-methoxydopa is known to be an important urinary metabolite of L-dopa in man (for review see Allen, 1973), and the present results confirm that it is also an important circulating metabolite. The presence of a substantial pool of 3-methoxydopa in the circulation and in body tissues may be of neuropharmacological importance in the treatment of Parkinsonism with L-dopa, since it has been suggested that 3methoxydopa may be metabolized in part by 0-demethylation to give rise to the parent drug (Bartholini et al., 1972).

The lack of correlation between plasma L-dopa concentrations and clinical improvement ratings has been reported by others (see Morris, 1973). This is perhaps related to the possibility that clinical improvement on L-dopa treatment is dependent on the variable degree of degenerative damage to dopaminergic systems in the basal ganglia of patients with Parkinsonism. Jéquier and Dufresne (1972) and Curzon (1973) reported that patients with the most severe impairment of normal dopaminergic function, as assessed by reduced concentrations of the dopamine metabolite homovanillic acid in the cerebrospinal fluid, were more likely to show significant improvement on treatment with L-dopa than those with less severe damage. Thus, because of the variability of the biochemical deficit in different patients, no simple correlation between oral dose or plasma concentration and therapeutic response could be expected.

We are grateful to Dr G. Bartholini, F. Hoffman La Roche and Co, for supplies of 3-0-methyl-dopa, and to Dr F. Geissbuhler for advice on the assay of this substance in plasma. The help of Dr A. W. Galbraith, of Geigy Pharmaceuticals Ltd, is also acknowledged in advising on the structure of the double-blind trial and in providing placebo Amantadine preparation.

\section{REFERENCES}

Allen, J. G. (1973). Plasma levels of levodopa and its metabolites. Advances in Progress in the Treatment of Parkinsonism, vol. 3, pp. 131-136. Edited by D. B. Calne. Raven Press: New York.

Andén, N.-E., Roos, B.-E., and Werdinius, B. (1963). On the occurrence of homovanillic acid in brain and cerebrospinal fluid and its determination by a fluorometric method. Life Sciences, 2, 448-458.

Bartholini, G., Kuruma, I., and Pletscher, A. (1972). The metabolic pathways of L-3-0-methyldopa. Journal of Pharmacology and Experimental Therapeutics, 183, 65-72.

Conover, N. J. (1971). Practical Non-parametric Statistics. Wiley: New York.

Curzon, G. (1973). Therapeutic effect of levodopa in relation to pretreatment amine metabolite concentration in cerebrospinal fluid. Advances in Neurology. Progress in the Treatment of Parkinsonism, vol. 3, pp. 165-172. Edited by D. B. Calne. Raven Press: New York.

Dallos, V., Heathfield, K., Stone, P., and Allen, F. A. D. (1970). Use of amantadine in Parkinson's disease. Results of a double-blind trial. British Medical Journal, 4, 24-26.

Dixon, W. J., and Massey, F. J. (1969). Introduction to Statistical Analysis, 3rd edn. McGraw-Hill: New York.

Draper, N. R., and Smith, H. (1966). Applied Regression Analysis. Wiley: New York.

Fahn, S., Prasad, A. L. N., and Delesie, R. (1972). A reliable and simple method for simultaneous determination of dopa and 3-0-methyl-dopa in plasma and brain. Analytical Biochemistry, 46, 557-575.

Godwin-Austen, R. B., Tomlinson, E. B., Frears, C. C., and 
Kok, H. W. L. (1969). Effects of L-dopa in Parkinson's disease. Lancet, 2, 165-168.

Guldberg, H. C., Sharman, D. F., and Tegerdine, P. R. (1971). Some observations on the estimation of 3-methoxytryptamine in brain tissue. British Journal of Pharmacology, 42, 505-511.

Jéquier, E., and Dufresne, J. J. (1972). Biochemical investigations in patients with Parkinson's disease treated with L-dopa. Neurology (Minneap.), 22, 15-21.

Morris, J. G. L. (1973). L-dopa tolerance tests in Parkinsonian patients. In Advances in Neurology. Progress in the Treatment of Parkinsonism, vol. 3, pp. 137-142. Edited by D. B. Calne. Raven Press: New York.

Parkes, J. D., Baxter, R. C., Galbraith, A., Marsden, C. D., and Rees, J. E. (1973). Amantadine treatment of Parkinson's disease. Advances in Neurology. Progress in the Treatment of Parkinsonism, vol. 3, pp. 105-114. Edited by D. B. Calne. Raven Press: New York.

Peaston, M. J. T., Bianchine, J. R., and Messiha, F. S. (1973). Effect of amantadine on L-2-14C-dopa metabolism in Parkinsonism. Life Sciences, 13, 237-246. 